\title{
Good Prospects
}

The ceramics industry has started the new year with a lot of momentum. The best example was the ceramitec 2018 trade fair from 10 to 13 April, which attracted more than 600 exhibitors from almost 40 countries to Munich. The latest technologies, plants and applications, materials and raw materials were presented. The participants from the ceramic and powder metallurgy industry were keen to invest and in a good mood.

The new special show and a lecture program on additive manufacturing were very well received, according to the trade fair organizer. Especially the topic of digitization and Industry 4.0 was on everyone's lips. The field of technical ceramics is already relatively far advanced. New possibilities for producing complex shapes in small quantities at low cost and of the highest quality are promising.

Additive manufacturing could revolutionize the production of ceramics, according to the industry. Both printers and innovative materials were presented. For example, nanoparticles made of metal and ceramics can now be produced using 3D printing. Material mixes will also make new applications possible, e.g. combinations of ceramic-metal or ceramic-plastics.
Plant construction was just as innovative, not only in $3 \mathrm{D}$ printing. The production of high-performance ceramics places corresponding demands on machines and furnaces. The control, but also the simulation of firing processes were much-noticed topics.

Incidentally, those hungry for information will soon be able to continue their visit to the fair: Tecnargilla will take place from 24 to 28 September in Rimini, Italy. This fair also presents on an international level - with companies from the fields of technical ceramics, refractory materials and ceramic building products such as tiles, bricks, stones, but also sanitary products and tableware. This year, the organizers also want to focus on the aesthetic trends in ceramic products; in addition, the topic of GreenTech was added. After all, saving time, energy and raw materials or avoiding emissions and waste in accordance with EU specifications (keyword: recycling management) are concerns that are increasingly coming to the fore for the ceramics industry as well.

As at ceramitec, the team of the two magazines INTERCERAM and Keramische Zeitschrift from Springer Fachmedien Wiesbaden GmbH will also be present at Tecnargilla. We would be glad to welcome you. 